\title{
Axonal Damage in Multiple Sclerosis Patients with High versus Low Expanded Disability Status Scale Score
}

\author{
Steven D. Brass, Sridar Narayanan, Jack P. Antel, Yves Lapierre, Louis Collins, \\ Douglas L. Arnold
}

\begin{abstract}
Background: The pathophysiological basis for differences in disability in patients with multiple sclerosis is unclear. Methods: We used magnetic resonance imaging to examine whether differences in disability in cohorts of multiple sclerosis patients with similar T2-weighted lesion volume and disease duration were associated with a more destructive disease process in the more disabled patients. Results: The benign and severely disabled groups had similar brain atrophy metrics and similar decreases of the neuronal marker, $\mathrm{N}$-acetylaspartate, in the normal appearing white matter of the cerebrum on magnetic resonance spectroscopy examination in vivo. The severely disabled cohort had more spinal cord atrophy. Conclusion: The dissociation of spinal cord atrophy and cerebral atrophy between these two groups suggests that the difference between the more benign and more disabled groups cannot be explained by a more aggressive pathological process that is affecting the entire neuroaxis in a homogeneous fashion.
\end{abstract}

\begin{abstract}
RÉSUMÉ: Comparaison du dommage axonal chez les patients atteints de sclérose en plaques ayant un score élevé ou un score bas à l'échelle étendue du statut d'invalidité. Introduction: La physiopathologie des différences dans le degré d'invalidité chez les patients atteints de sclérose en plaques est mal connue. Méthodes: Nous avons utilisé l'imagerie par résonance magnétique pour évaluer si les différences observées dans le degré d'invalidité chez des cohortes de patients atteints de sclérose en plaques dont le volume des lésions à l'examen pondéré en T2 et la durée de maladie étaient similaires, étaient associées à un processus morbide plus destructeur chez les patients les plus invalides. Résultats: Que l'invalidité soit légère ou grave, la mesure de l'atrophie cérébrale et la diminution du marqueur neuronal $\mathrm{N}$-acétyl aspartate dans la matière blanche du cerveau, à la spectroscopie par résonance magnétique in vivo, étaient similaires dans les deux groupes. La cohorte ayant le degré d'invalidité le plus élevé avait plus d'atrophie au niveau de la moelle épinière. Conclusion: La dissociation entre l'atrophie de la moelle épinière et l'atrophie cérébrale chez ces deux groupes de patients suggère que la différence entre le groupe ayant une invalidité légère et celui ayant une invalidité plus marquée ne peut s'expliquer par un processus pathologique plus agressif touchant de façon homogène tout l'axe neural.
\end{abstract}

Can. J. Neurol. Sci. 2004; 31: 225-228

The bases for the neurological disability in multiple sclerosis continues to be defined. Expanded Disability Status Scale (EDSS) scores that reflect impaired walking are suggested to largely reflect spinal cord injury, as there is relatively poor correlation of disability with T2-weighted (T2W) lesion burden in the brain. ${ }^{1-3}$ There is a somewhat better correlation between disability and measures of tissue destruction in the brain including reduced $\mathrm{N}$-acetylaspartate (NAA) (a measure of axonal injury) in the normal-appearing white matter (NAWM) ${ }^{4}$ chronic T1-weighted hypointense lesions (black holes) ${ }^{5}$ and atrophy. ${ }^{6}$ In this study we evaluated two patient groups ("benign" and "disabled") selected on the basis of having wide variation in neurological disability despite having similar T2W brain lesion volumes. In view of a recent report that, despite heterogeneity of multiple sclerosis (MS) pathology amongst patients, the pathological process is homogeneous with individual patients, ${ }^{7}$ we wished to determine whether the more disabled patients would show evidence of a more tissue destructive process that

From the Montreal Neurological Hospital, Department of Neurology and Neurosurgery, Montreal, Quebec, Canada.

Received August 26, 2002. ACCEPtedinfinalform September 11, 2003. Reprint requests to: Douglas L. Arnold, Montreal Neurological Hospital, Department of Neurology and Neurosurgery, 3801 University Street, Montreal, Quebec H3A2B4, Canada 
was widespread and uniform throughout the neuraxis. We therefore predicted that the more disabled cohort would demonstrate evidence of more spinal cord injury as determined by the extent of magnetic resonance imaging (MRI)-defined spinal cord atrophy. To assess this, we measured the density of the neuronal marker compound, NAA in deep central white matter of the brain, as well as global brain atrophy. If differences in the destructiveness of MS pathology are responsible for differences in disability and the pathology is homogeneous within an individual, then patients with greater disability would be expected to have lower density of NAA and greater cerebral atrophy for a given cerebral lesion volume.

Since the benign group had relatively low cerebral lesion volumes, matching the groups for cerebral lesion volume had the effect of selecting for low cerebral lesion volume in both the benign and disabled groups. This meant that $>95 \%$ of the spectroscopic volume of interest (VOI) used for spectroscopy was composed of NAWM. Technical limitations do not allow us to derive information about the NAA density in lesions that comprise such a small proportion of brain volume. Therefore, our measurements of NAA in deep central brain essentially reflect the situation in NAWM. Since NAAdensity in lesions and NAWM decreases nonlinearly over the course of MS, 8,9 we matched patients for disease duration, as well.

\section{MethodS}

\section{Study population}

Data from 25 patients with clinically definite MS were reviewed: 13 had benign $\mathrm{MS}$ (EDSS $\leq 3.0$, disease duration $\geq 10$ years) and 12 had disabling MS (EDSS $=5$ - 8.5 inclusively, disease duration $\geq 10$ years). ${ }^{10}$ We obtained the benign and disabled groups by retrospectively looking back at the Montreal Neurological Institute MS-magnetic resonance spectroscopy (MRS) database of patients who had previously undergone combined MRI/MRS exams. We then identified the disabled group by selecting patients who had $\mathrm{T} 2 \mathrm{~W}$ lesion loads and disease duration that were similar to those of the benign group, but a higher EDSS score (5 - 8.5). The group of patients with disabling MS was composed of two patients with relapsingremitting disease and 10 patients with secondary-progressive MS. A group of 15 normal volunteers served as control subjects. Radiological data were examined to determine T2W lesion volume, NAA:creatine ratio (NAA/Cr), spinal cord crosssectional area, and demographics in all three cohorts (Table). Informed consent was obtained from all subjects.

\section{Proton MRI and MRS of brain}

Combined MRI and MRS examinations of the brain were obtained in a single session for each examination using a scanner operating at $1.5 \mathrm{~T}$ (Philips Gyroscan). A transverse dual echo, turbo spin-echo sequence [repetition time (TR), 2075 milliseconds; echo times 32 and 90 milliseconds, 256 × 256 matrix, 1 signal average, 250-mm field of view] yielding proton density-weighted and T2Wimages with 50 contiguous slices was acquired parallel to the line connecting the anterior and posterior commissures. The MRIs were used to select an intracranial volume of interest (VOI) for spectroscopy measuring approximately $90 \mathrm{~mm}$ anteroposteriorly by $20 \mathrm{~mm}$ cranio-
Table: Demographics of the Cohort.

\begin{tabular}{|c|c|c|c|}
\hline & $\begin{array}{l}\text { Controls } \\
(n=15)\end{array}$ & $\begin{array}{l}\text { Benign MS } \\
(n=13)\end{array}$ & $\begin{array}{l}\text { Disabled MS } \\
(\mathrm{n}=12)\end{array}$ \\
\hline \multicolumn{4}{|l|}{ Age (years) } \\
\hline Mean (SD) & $39(8)$ & $39(5)$ & $45(9)$ \\
\hline \multicolumn{4}{|l|}{ EDSS } \\
\hline Median (Range) & - & $1.5(0-2.5)$ & $7(5-8.5)$ \\
\hline \multicolumn{4}{|c|}{ Disease Duration (years) } \\
\hline Mean (SD) & - & $15(5)$ & $17(5)$ \\
\hline \multicolumn{4}{|l|}{ Cerebral T2W LV (cc) } \\
\hline Mean (SD) & - & $5.4(3.5)$ & $8.7(4.8)$ \\
\hline \multicolumn{4}{|c|}{$\%$ VOI Occupied by Lesion } \\
\hline Mean (SD) & - & $2.4(1.9)$ & $3.2(1.8)$ \\
\hline
\end{tabular}

caudally by $90 \mathrm{~mm}$ left to right. This VOI was centred on the corpus callosum to include mostly white matter and some mesial cortex of both hemispheres. Two-dimensional spectroscopic images were obtained using a PRESS sequence (TR, 2000 milliseconds; TE 272 milliseconds; $250-\mathrm{mm}$ field of view; $32 \mathrm{x}$ 32 phase encoding steps; 1 signal average per step) as previously described. ${ }^{9}$

\section{Measurement of spinal cord atrophy}

High resolution T1-weighted imaging of the spinal cord was used to accurately assess spinal cord cross-sectional area at the level of C2 as previously described by Narayanan et al. ${ }^{11}$

\section{Measurements of the brain to intracranial capacity ratio}

The brain to intracranial capacity ratio (BICCR) is calculated from the volume of automatically segmented cerebrospinal fluid, grey matter, white matter, and lesions, as previously described by Collins et al. ${ }^{12}$ The BICCR is the ratio obtained by dividing the sum of the volumes of (grey matter + white matter + lesion) by the sum of the volumes of (grey matter + white matter + lesion + cerebrospinal fluid).

\section{Data analysis}

$\mathrm{N}$-acetylaspartate values were expressed relative to intravoxel $\mathrm{Cr}$ to compensate for machine-dependent variations of signal intensity over the VOI. The NAA/Cr ratios for all the voxels in the spectroscopic VOI (excluding edge voxels containing spectra that were artifactually distorted) were then averaged to obtain a summary NAA/Cr ratio for each subject. Central brain NAA/Cr values and spinal cord cross sectional areas were compared across groups using analysis of variance followed by pairwise post hoc comparison using the Tukey honestly significant difference procedure to account for multiple comparisons. Data were considered significant at the 0.05 level. 


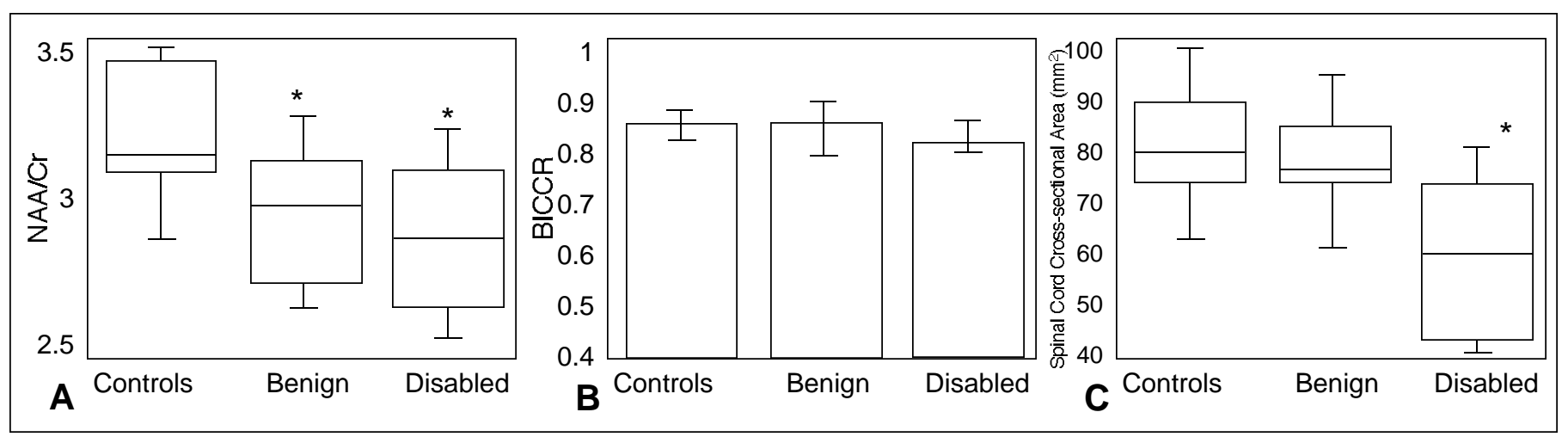

Figure: Composition of patients with benign and disabling MS matched for T2W lesion volume and duration of disease. (A) NAA/Cr in the volume of interest (B) Cerebral atrophy as assessed by BICCR (C) Spinal cord cross-sectional area at the second cervical level. The asterix (*) denotes significantly different from controls.

\section{RESULTS}

A retrospective review was carried out on $11 / 13$ benign patients and 11/12 disabled patients with respect to clinical presentation and course of illness. Among the benign group, only $1 / 11$ had relapses involving motor dysfunction compatible with myelopathy whereas 10/11 had sensory related relapses. In the disabled group, 8/11 had relapses involving motor dysfunction compatible with spinal cord involvement whereas $3 / 11$ had recurrent events involving brainstem rather than clearcut motor dysfunction in the limbs. Cerebral NAA/Cr ratios, BICCR values and the spinal cord cross-sectional areas for the three cohorts are summarised in the Figure. The mean cerebral NAA/Cr ratio in a volume of interest centred on the corpus callosum containing mostly normal appearing white matter was not different in the patients with benign MS compared to disabling MS ( $p>0.44$ ). Despite having low T2W lesion volume, both the benign and disabled group had low brain NAA/Cr compared to the normal control group $(\mathrm{p}<0.003)$. The BICCR values did not differ among the benign, disabled and control groups $(p>0.16)$. The disabled group had significantly smaller mean spinal cord crosssectional area at the level of $\mathrm{C} 2$ than the benign group $(\mathrm{p}=0.006)$ and controls ( $p>0.001)$. Cord cross-sectional area did not differ between the benign and the control groups ( $>0.45$ ).

\section{Discussion}

Our study compared cohorts of patients with benign and disabling multiple sclerosis with similar cerebral lesion loads and disease durations in order to determine the factor responsible for differences in their disability. The cytodestructive process in the brains of the disabled group of patients was not found to be any more severe than that of the benign group, based on measures of cerebral NAA/Cr and BICCR, neither of which showed statistically significant differences between the benign and disabled groups. The low cerebral $\mathrm{NAA} / \mathrm{Cr}$ in both our benign and disabled groups, compared to control subjects, indicates that significant axonal pathology was present in both. Given that T2W lesions occupied only $2.4 \%$ and $3.2 \%$ of the VOI in the benign and disabled groups, respectively, the observed decreases of central brain NAA/Cr in both patient groups must reflect primarily reduction of $\mathrm{NAA} / \mathrm{Cr}$ in normalappearing white matter. ${ }^{8}$

The difference in disability between the benign and disabled patients in this cohort appear to be due to the development of spinal cord pathology rather than differences in the degree of cerebral tissue injury. A retrospective review of the clinical course of patients demonstrated that patients in the disabled group acquired disability from progressive disease rather than from one single destructive attack in the spinal cord. Four patients of the high disability cohort had early relapses with motor involvement compatible with spinal cord involvement contributing to the progressive disability. Among the low disability group, only one patient presented with myelopathy whereas others had mainly sensory symptomatology. When comparing both groups, patients who suffered from attacks involving spinal cord-related motor dysfunction were more likely to go on to secondary progressive disease and become disabled than those patients who had purely sensory findings likely pointing to a more benign course of disease. This is consistent with previous prognostic guides in multiple sclerosis which demonstrated that early onset sensory symptoms versus a course involving residual motor signs is one of the factors associated with a more benign prognosis..$^{10}$ The severely disabled cohort had more spinal cord atrophy, suggesting that more spinal cord injury had occurred in the more disabled cohort. This reinforces the importance of relapses and lesion location ${ }^{13,14}$ as causes of disability as opposed to widespread, homogeneous destructive pathological processes that are more severe throughout the central nervous system of patients with greater disability. The amount of tissue destruction was dissociated between the brain and spinal cord in our patient groups. Further imaging and histological studies will be required to establish whether this dissociation is a result of the quantity of spinal cord lesions or heterogeneity of the disease process at different sites of the neuroaxis.

\section{REFERENCES}

1. Thompson AJ, Kermode AG, MacManus DG, et al. Patterns of 
disease activity in multiple sclerosis: clinical and magnetic resonance imaging study. Br Med J 1990;200:631-634.

2. Miller DH, Grossman RI, Reingold SC, McFarland HF. The role of magnetic resonance techniques in understanding and managing multiple sclerosis. Brain 1998;121:3-24.

3. Filippi M, Patty DW, Kappos L, et al. Correlations between changes in disability and T2-weighted brain and MRI activity in MS: a follow-up study. Neurology 1995;45:255-260.

4. De Stefano N, Matthews PM, Antel JP, et al. Chemical pathology of acute demyelinating lesions and its correlation with disability. Ann Neurol 1995;38:901-909.

5. Iannucci G, Minicucci L, Rodegher M, et al. Correlations between clinical and MRI involvement in multiple sclerosis: assessment using T(1), T(2) and MThistograms. J Neurol Sci 1999; 171:121129.

6. Rudick RA, Fisher E, Lee JC (Multiple Sclerosis Collaborative Research Group), et al. Use of the brain parenchymal fraction to measure whole brain atrophy in relapsing-remitting MS. Neurology 1999;53:1698-1704.

7. Lucchinetti C, Bruck W, Parisi J, et al. Heterogeneity of multiple sclerosis lesions: implications for the pathogenesis of demyelination. Ann Neurol 2000; 47:707-717.
8. Fu L, Matthews PM, De Stefano N, et al. Imaging axonal damage of normal-appearing white matter in multiple sclerosis. Brain 1998;121:103-113.

9. De Stefano N, Narayanan S, Francis GS, et al. Evidence of axonal damage in the early stages of multiple sclerosis and its relevance to disability. Arch Neurol 2001;58;65-70.

10. Paty DW, Ebers GC. Clinical features. In: Paty DW, Ebers GC (Eds.) Multiple Sclerosis. Philadelphia: FA Davis 1998: 151-152.

11. Narayanan S, De Stefano N, Francis S, et al. Disease Duration Influences the Relationship between Brain Axonal Injury, Spinal Cord Atrophy and Disability in Multiple Sclerosis. Proceedings from Annual Meeting of International Socciety for Magnetic Resonance in Medicine. 2000:1297. Abstract.

12. Collins DL, Narayanan S, Caramanos Z, et al. Relation of cerebral atrophy in multiple sclerosis to severity of disease and axonal injury. Neurology 2000;54: A17.

13. Honig LS, Sheremata WA. Magnetic resonance imaging of spinal cord lesions in multiple sclerosis. J Neurol Neurosurg Psychiatry 1989;52:459-466.

14. Kidd D, Thorpe JW, Thompson AJ, et al. Spinal cord MRI using multi-array coils and fast spin echo II. Findings in multiple sclerosis. Neurology 1993;43:2632-2627. 